\title{
Should Transcatheter Aortic Valve Implantation Be the First-Choice Treatment? An Important Step Forward
}

\author{
Kentaro Hayashida, MD, PhD
}

$\mathbf{T}$ ranscatheter aortic valve implantation (TAVI) has emerged as a well-established treatment for patients with high- and intermediate-surgical risk symptomatic severe aortic stenosis (AS). ${ }^{1}$

This new therapeutic option was introduced in Japan in 2012, and now prevails nationwide. ${ }^{2}$ Recently, several randomized control trials (RCTs) have shown non-inferiority or superiority of TAVI over surgical aortic valve replacement (SAVR) in surgical low-risk cohorts. ${ }^{3,4}$ Based on these results, TAVI in low-risk cohorts is now approved in the US and Europe, and the extension of TAVI to low-risk cohorts is common around the world.

However, there remains a paucity of data about comparisons of TAVI and SAVR in Japanese cohorts.

In this issue of the Journal, Takeji et al compare 2-year clinical outcomes between TAVI and SAVR in a Japanese multicenter registry. ${ }^{5}$ In that study, the authors investigated 2-year all-cause mortality and heart failure hospitalization in matched TAVI and SAVR cohorts comprising 306 patients. The TAVI cohort consisted of patients who received Sapien XT from the K-TAVI registry enrolled from 2013 to $2016 .^{6}$ The SAVR cohort consisted of patients from the CURRENT-AS registry from 2003 to $2011 .{ }^{7}$ The authors have already published several important studies from both registries conducted by Kyoto University and its affiliated hospitals, in particular a study of the advantage of initial surgical strategy in asymptomatic AS patients that has had a huge impact on global guidelines and daily practice. $^{7}$

Importantly, that study ${ }^{7}$ was the first to compare TAVI and SAVR in real-world practice in Japan, and provides robust data in our own cohort. However, the study does have some limitations. First, the previous version of the balloon expandable valve (Sapien XT) was used for the TAVI cohort in that study, thus the transfemoral approach was limited to only $62.1 \%$ of patients. However, the 30 -day and 2-year all-cause mortality was only $1.3 \%$ and $13.7 \%$, respectively. ${ }^{7}$ This result is better than that reported in previous studies and demonstrated favorable TAVI outcomes in Japan. With the current version of TAVI devices (Sapien 3 and Evolut R/Pro), a higher rate of transfemoral approaches may result in improved clinical outcomes, and comparisons between TAVI and SAVR using contemporary devices and techniques could be of great interest in a future study. Second, the age and surgical risk were

\section{Article p 806}

significantly higher in the TAVI than SAVR, even after propensity matching, presumably due to the study design combining the 2 different registries. ${ }^{7}$ Complete matching of these important basic backgrounds could have led to different and more provocative results.

Now the question is "should TAVI be the treatment of first choice?" Based on the results of 2 independent RCTs in low-risk cohorts, ${ }^{\mathbf{1}, 4}$ the US Food and Drug Administration (FDA) approved TAVI for use in low-risk patients, followed by approval in Europe in 2019. That means TAVI is now approved in all patients regardless of surgical risk. However, some challenges remain. First, data on long-term clinical outcome and durability of TAVI devices remain scarce. Indeed, 5-year outcomes of the PARNTER 2 study demonstrated late catch-up of mortality and stroke in the TAVI cohort, presumably due to a higher incidence of moderate to severe paravalvular leak (PVL). ${ }^{8}$ In addition, the importance of decreasing PVL after TAVI, even in a contemporary TAVI cohort, to reduce the incidence of rehospitalization due to heart failure has been demonstrated. ${ }^{9}$ The latest version of TAVI devices, meticulous screening, and procedural modification may improve clinical outcomes. It is also important to understand that "low risk" does not necessarily means "young age". Given the limited data on the durability of TAVI bioprosthesis, careful consideration should be given to shift towards younger patients, especially in the Japanese cohort with longer life expectancy. Second, the need for a permanent pacemaker, as well as unfavorable anatomy for TAVI (left ventricular outflow tract calcification, severely calcified bicuspid valve, etc.), could be remaining issues that hinder the unlimited application of TAVI to low-risk cohorts. Subclinical leaflet thrombosis and an optimal antithrombotic strategy after TAVI remain of vital importance and are still to be solved. ${ }^{10}$ Concomitant diseases (mitral, tricuspid, coronary, etc.) should also be taken into account when choosing the treatment option for patients with AS.

Now we are welcoming a major update in the Japanese guidelines on valvular heart disease in the upcoming Japanese Society of Cardiology 2020 annual meeting. The main concept is that the surgical risk score is no longer the gatekeeper regarding treatment choice for patients with

The opinions expressed in this article are not necessarily those of the editors or of the Japanese Circulation Society.

Received March 2, 2020; accepted March 5, 2020; J-STAGE Advance Publication released online March 28, 2020

Department of Cardiology, Keio University School of Medicine, Tokyo, Japan

Mailing address: Kentaro Hayashida, MD, PhD, FESC, FACC, FJCS, Department of Cardiology, Keio University School of

Medicine, 35 Shinanomachi, Shinjuku-ku, Tokyo 160-8582, Japan. E-mail: k-hayashida@umin.ac.jp

ISSN-1346-9843 All rights are reserved to the Japanese Circulation Society. For permissions, please e-mail: cj@j-circ.or.jp 
AS. Heart team discussion respecting patient preferences and values and informed consent of all AS patients taking into account up-to-date evidence from our own country is of paramount importance. Our Optimized CathEter vAlvular iNtervention (OCEAN)-TAVI registry is also working rigorously to publish evidence based on the Japanese cohort (UMIN000020423).

The study of Takeji et $\mathrm{al}^{\mathbf{5}}$ published in this issue of the Journal is an important step forward, as continuous and relentless efforts should be made to publish data from our country.

\section{Conflict of Interest}

$\mathrm{K} . \mathrm{H}$. is a clinical proctor for Edwards Lifesciences and is a member of Circulation Journal' Editorial Team.

\section{References}

1. Leon MB, Smith CR, Mack MJ, Makkar RR, Svensson LG, Kodali SK, et al. Transcatheter or surgical aortic-valve replacement in intermediate-risk patients. N Engl J Med 2016; 374: 16091620.

2. Yamamoto M, Watanabe $\mathrm{Y}$, Tada N, Naganuma T, Araki M, Yamanaka $\mathrm{F}$, et al. Transcatheter aortic valve replacement outcomes in Japan: Optimized CathEter vAlvular iNtervention (OCEAN) Japanese multicenter registry. Cardiovasc Revasc Med 2019; 20: 843-851.

3. Mack MJ, Leon MB, Thourani VH, Makkar R, Kodali SK, Russo M, et al. Transcatheter aortic-valve replacement with a balloon-expandable valve in low-risk patients. $N$ Engl $J$ Med 2019; 380: 1695-1705.

4. Popma JJ, Deeb GM, Yakubov SJ, Mumtaz M, Gada H, O'Hair D, et al. Transcatheter aortic-valve replacement with a self-expanding valve in low-risk patients. N Engl J Med 2019; 380: $1706-1715$.

5. Takeji Y, Taniguchi T, Morimoto T, Saito N, Ando K, Shirai S, et al; on befalf of the CURRENT AS Registry Investigators and K-TAVI Registry Investigators. Transcatheter aortic valve implantation vs. surgical aortic valve replacement for severe aortic stenosis in real-world clinical practice. Circ $J$ 2020; 84: 806-814.

6. Takimoto S, Saito N, Minakata K, Shirai S, Isotani A, Arai Y, et al. Favorable clinical outcomes of transcatheter aortic valve implantation in japanese patients: First report from the postapproval K-TAVI Registry. Circ J 2016; 81: 103-109.

7. Taniguchi T, Morimoto T, Shiomi H, Ando K, Kanamori N, Murata K, et al. Initial surgical versus conservative strategies in patients with asymptomatic severe aortic stenosis. $\mathrm{J} \mathrm{Am} \mathrm{Coll}$ Cardiol 2015; 66: 2827-2838.

8. Makkar RR, Thourani VH, Mack MJ, Kodali SK, Kapadia S, Webb JG, et al. Five-year outcomes of transcatheter or surgical aortic-valve replacement. N Engl J Med 2020; 382: 799-809.

9. Yoshijima N, Yanagisawa R, Hase H, Tanaka M, Tsuruta H, Shimizu H, et al. Update on the clinical impact of mild aortic regurgitation after transcatheter aortic valve implantation: Insights from the Japanese multicenter OCEAN-TAVI registry. Catheter Cardiovasc Interv 2020; 95: 35-44.

10. Yanagisawa R, Tanaka M, Yashima F, Arai T, Jinzaki M, Shimizu $\mathrm{H}$, et al. Early and late leaflet thrombosis after transcatheter aortic valve replacement. Circ Cardiovasc Interv 2019; 12: e007349. 